\title{
Sciendo
}

DOI: $10.1515 /$ sspjce-2019-0021

\section{Improvement of cement stabilized structural lateritic with pulverized snail shell}

\author{
Oluwaseun Adetayo, Olugbenga Amu, Sunday Alabi \\ Federal University Oye Ekiti, Ekiti State Nigeria \\ Faculty of Engineering Department of Civil Engineering \\ email: oluwaseun.adetayo@fuoye.edu.ng; tayo.seun4real@gmail.com
}

\begin{abstract}
This study investigated the suitability of pulverized snail shell (PSS) as partial replacement of cement stabilized soil in foundation constructions. Preliminary and engineering tests were carried out on the soil samples. The optimum cement content fixed at $11 \%$ in correlation to Unified Soil Classification System, the PSS was introduced at varying percentages of $2 \%, 4 \%, 6 \%, 8 \%$ and $10 \%$. Results revealed that, addition of PSS and $11 \%$ cement to lateritic soil caused a reduction in both liquid limits and plasticity index and an increased in plastic limits for all samples. Engineering tests showed the maximum dry density at optimum cement increased from $1493.34 \pm 103.58$ $\mathrm{kg} \cdot \mathrm{m}^{-3}$ to $1632 \pm 435.81 \mathrm{~kg} \cdot \mathrm{m}^{-3}$ for sample $\mathrm{A} ; 1476.77 \pm 367.51 \mathrm{~kg} \cdot \mathrm{m}^{-3}$ to $1668 \pm 202.58 \mathrm{~kg} \cdot \mathrm{m}^{-3}$ for sample B; $1460.77 \pm 623.58 \mathrm{~kg} \cdot \mathrm{m}^{-3}$ to $1651 \pm 135.45 \mathrm{~kg} \cdot \mathrm{m}^{-3}$ for sample C. The CBR recorded highest value at $4 \% \mathrm{PSS}$ optimum cement for all samples. The addition of pulverized snail shell increased the strength of cement stabilized lateritic soil for structural foundation construction.
\end{abstract}

Keywords: pulverized snail shell, cement stabilization, lateritic soil, structural foundation

\section{Introduction}

The problems with foundation on soils have included cracking, heaving and break up of pavements, building foundation, slab members, etc. as a result of these problems associated with poor soils, various methods are being developed worldwide to treat these soils is known as soil stabilization. Weak soils usually are attributed to excess ingression of groundwater, high shrinkage and swelling potential, high liquid limit and plasticity index and lack of strength. All these defects are usually associated to deformable properties of the soil. Murthy [1], observed that, treatment of weak soils can be done by preventing ingress of ground water flow or removing it from the site in question, or improving soil strength through a mechanical medium or chemical medium on the other hands. Cuneyt [2], similarly states that, if such soil cannot be removed, then its engineering behavior properties can be enhanced by suitable method of ground treatment. Das [3], states that soils with low strength are highly deformable, lack of strength leads to soil failure if overloaded. However, this has been frequent in occurrence in 
civil engineering construction work due to some act of negligence being put up by some engineer when such problems are being encountered.

The various methods used to alter or improve soil properties such as their strength, settlement and bearing capacity are generally called soil stabilization techniques, which objectives are to improve on the volume stability, strength and stress-strain properties, permeability and durability. The concept of soil improvement or modification through stabilization with the use of additives has been around for several thousands of years. Although this process of improving the engineering properties of soils has been practiced for centuries, soil stabilization did not gain significance until after World War II [4]. Thousands of years ago, soils have already been stabilized with lime and other relevant available pozzolans. It has been proven that the benefits of using pozzolans materials in soil stabilization are both economic and technical. Several studies have been made on soil stabilization using different stabilizing agents. Pyne [5], showed the effectiveness of addition of calcium chloride to soil treatment. Lopez and Castano [6] used calcium oxide as a stabilization technique clay soils in order to inhibit its expansion contraction properties. Ghafoori and Cai [7], used coal combustion by-products in roller compacted concrete, roadway and parking lots. Muntohar and Gendut [8] and Muntohar [9], investigated the effect of fly ash and pozzolanic material on soil improvement. The use of pulverized snail shell as a soil stabilizer is not a common practice worldwide but research findings have shown the immense benefit and potential of using snail shell powder as pozzolans in soil.

However, much researches have not been done on the performance of pulverized snail shell on cement stabilized soil. Snail shell gotten from the consumption of fleshy edible part of snail is a waste product that can lead to land population if not effectively managed. The shell comes in form of V-shaped spiral shell found in many coastal regions, especially here in Nigeria. The shells are a strong, hard and brittle material. The shells constitute waste and its disposal is posing problems in areas where they have no use for it [10]. It is in this light that this experimental study seeks to investigate into the suitability of pulverized snail shell as a complement for cement in soil stabilization by way of considering the effects of pulverized snail shell on cement-stabilized lateritic soil.

\subsection{Lateritic Soils}

Lateritic soils, one of the least fertile soil types, are found in wetter and hotter climates [11]. Lateritic soils may contain clay minerals but they tend to be silica-poor, for silica is leached out by waters passing through the soil. Typical laterite is porous and claylike. It contains the iron oxide minerals goethite $\mathrm{FeO}(\mathrm{OH})$, lepidocrocite $\mathrm{FeHO}_{2}$, and hematite $\mathrm{Fe}_{2} \mathrm{O}_{3}$. It also contains titanium oxides and hydrated oxides of aluminum, the most common and abundant of which is gibbsite $\mathrm{Al}(\mathrm{OH})_{3}$. The aluminum-rich representative of laterite is bauxite. Laterite is frequently pisolitic (pealike). Exposed surfaces are blackish-brown to reddish and commonly have a slaggy, or scoriaceous, lavalike appearance. Commonly lighter in colour (red, yellow, and brown) where freshly broken, it is generally soft when freshly quarried but hardens on exposure. Laterite is not uniquely identified with any particular parent rock, geologic age, single method of formation, climate per se, or geographic location. It is a rock product that is a response to a set of physiochemical conditions, which include an iron-containing parent rock, a well-drained terrain, and abundant moisture for hydrolysis during weathering, relatively high oxidation potential, and persistence of these conditions over thousands of years. 
Laterite is a very widespread soil group. Lateritic soils occur in all wet tropical regions, e.g. East, West and Central Africa, Indonesia, Thailand, Brazil and various island such as Hawaii and Cuba Lateritic soils are residual soils formed in hot, wet tropical regions with an annual rainfall between $750 \mathrm{~mm}$ and $3000 \mathrm{~mm}$ or more. The main soil forming process consists of intensive weathering with leaching of bases and silica resulting in a relative accumulation of iron and aluminum oxides and formation of kaolinitic clays. Intensive weathering producing deep Laterite profile occurs on flat slopes in the terrain where runoff is limited.

Laterite mainly occurs as:

- Surface deposits of unhardened, clayey soils

- Massive rock- like hardpans

- Gravel consisting of concretionary nodules in a soil matrix.

\subsection{Soil Improvement}

In foundation engineering practice the soils at a given site are often less than ideal for the intended purpose. They may be weak, highly compressible, or have a higher permeability than desirable from an engineering or economic point of view. It would seem reasonable in such instances to simply relocate the structure or facility. However, considerations other than geotechnical often govern the location of a structure, and the engineer is forced to design for the site at hand. One possibility is to adapt the foundation to the geotechnical conditions at hand or otherwise to try to stabilize or improve the engineering properties of the soils at the site. Depending on the circumstances, this second approach may be the most economical solution to the problem. Stabilization is the process of blending and mixing materials with a soil to improve the pertinent properties of the soil. The process may include the blending of soils to achieve a desired gradation or the mixing of commercially available additives that may alter the gradation, change certain properties, or act as a binder for cementation of the soil. Stabilization is usually mechanical or chemical, thermal and electrical stabilization have occasionally been used or considered.

Mechanical stabilization or densification is also called compaction. Chemical stabilization includes the mixing or injecting of chemical substances into the soil. Portland cement, lime, asphalt, calcium chloride, sodium chloride and paper mill waste are common chemical stabilization agents. Other methods of stabilizing unsuitable foundation soils include dewatering which is the removal or reduction of unwanted excess ground water pressure, and preloading, in which the foundation soil are surcharged with a temporary overload so as increase the strength and decrease anticipated settlement [12].

\subsection{Pozzolanic Reaction}

Pozzolans are siliceous or siliceous and aluminous materials which in themselves do not possess any cementitious value but in finely divided form and in the presence of moisture will chemically react with calcium hydroxide $(\mathrm{CH})$ to form a compound with cementitious value according to this general equation:

$$
\mathrm{Ca}(\mathrm{OH})_{2}+\mathrm{H}_{4} \mathrm{SiO}_{4} \rightarrow \mathrm{Ca}^{2+}+\mathrm{H}_{2} \mathrm{SiO}_{4}{ }^{2-}+2 \mathrm{H}_{2} \mathrm{O} \rightarrow \mathrm{CaH}_{2} \mathrm{SiO}_{4} \cdot 2 \mathrm{H}_{2} \mathrm{O}
$$


Which can be summarized in abbreviated notation of silicate chemists;

$$
\text { Pozzolans }+\mathrm{CH} \rightarrow \mathrm{C}-\mathrm{S}-\mathrm{H}
$$

Calcium silicate hydrates $(\mathrm{C}-\mathrm{S}-\mathrm{H})$ is the strength-forming products of cement hydration. Pozzolans can be classified as artificial if firing (or calcination) is required to induce pozzolanicity and natural if no calcination is required. The product of general formula $\left(\mathrm{CaH}_{2} \mathrm{SiO}_{4}\right.$. $2 \mathrm{H}_{2} \mathrm{O}$ ) formed is a calcium silicate hydrate, also abbreviated as $\mathrm{CSH}$ in cement chemist notation. The ratio $\mathrm{Ca} / \mathrm{Si}$, or $\mathrm{C} / \mathrm{S}$, and the number of water molecules can vary and the above mentioned stoichiometry may differ. As the density of CSH is lower than that of portlandite and pure silica, a consequence of this reaction is a swelling of the reaction products. This reaction may also occur with time in concrete between alkaline cement pore water and poorlycrystalline silica aggregates. This delayed process is also known as alkali silica reaction, or alkali-aggregate reaction, and may seriously damage concrete structures because the resulting volumetric expansion is also responsible for spalling and decrease of the concrete strength. The pozzolanic reaction may be slower than the rest of the reactions that occur during cement hydration, and thus the short-term strength of concrete made with pozzolans may not be as high as concrete made with purely cementitious materials; conversely, highly reactive pozzolans, such as silica fume and high reactivity metakaolin can produce "high early strength" concrete that increase the rate at which concrete gains strength.

\section{Materials and Methods}

The materials used include lateritic soil samples, Ordinary Portland cement, pulverized snail shell and water. The lateritic soil samples were collected from burrow pits within Obafemi Awolowo University along Road 7, Ile-Ife in Osun State Nigeria. These were designated as samples A, B and C. The soil samples pre-treatment was ensured before the commencement of the study. For easy identification of the soil samples, tags were placed on them to describe their dates of excavation, depths of excavation from the source and locations. The soil samples were spread on sacks in the laboratory to air-dry them for a minimum of two weeks, preventing water contamination and direct sunlight contact and local drying was prevented by frequently turning of the sacks of soil samples. This was later sieved with sieve No. 4 (4.76mm opening) to obtain the final soil sample. The required quantity of Ordinary Portland cement manufactured by West African Portland Cement Plc (WAPCO) Ota, Ogun State was obtained locally, and kept in a safe platform to prevent any contact with moisture and any other external affection of its properties. Portable mixing water was obtained from treated water available in the laboratory. The pulverized snail shells were obtained from snail shells (fig. 1.) collected from different locations in Ibadan area. The fleshy parts were removed from the shell, then the empty shells were thoroughly washed, air-dried for one week and calcined in an electric muffle furnace at $850^{\circ} \mathrm{C}$. It was then grounded into fine powder particles form with the aid of ball milling machine. The ash obtained was later sieved through $75 \mu \mathrm{m}$ and kept in a sack bag to prevent it from moisture and any other external influences that can affect its properties as specified in both BS:1924 [13] and ASTM C618-93 [14] requirements. 


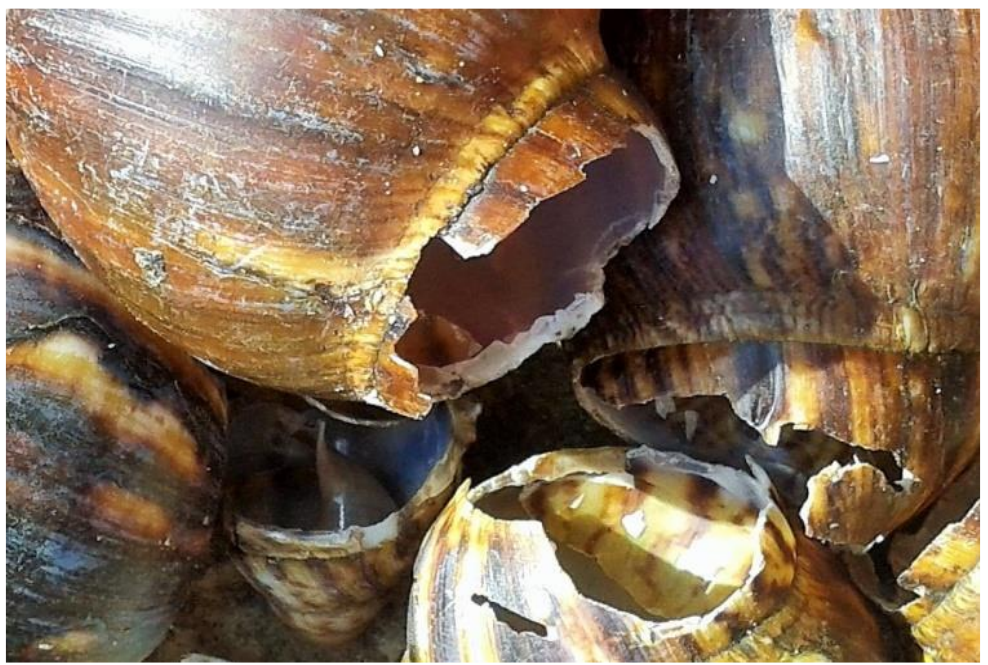

Figure 1: Snail Shells (Locally sourced)

Preliminary tests such as the natural moisture content, specific gravity, particle size analysis and Atterberg's limits were carried out on three unstabilized soil samples to determine their index properties. The cement being the major stabilizing material, was thoroughly mixed with the soil samples at a fixed dosage of $11 \%$ with respect to the soil classification and varying percentages of $(2,4,6,8 \& 10 \%)$ of the pulverized snail shell by weight of the soil samples. This was done in conjunction with the liquid limit and the determined plasticity index (PI) from Atterberg's limit test. The point of lowest PI gives the optimum amount of cement required. Hence, engineering properties of cement stabilized soil was determined. These engineering properties are used as the control against which the engineering properties of cement stabilized lateritic soil modified with pulverized snail shell are compared. The main objective of the study is to determine the change in the engineering properties of the stabilized soil sample modified with pulverized snail shell.

Engineering tests such as compaction, California bearing ratio (CBR) and undrained traixial were also performed on soil samples at their natural states, when stabilized with optimum cement and when pulverized snail shell (PSS) was introduced as pozollan to the samples. The various tests were carried out with standard procedures stipulated in BS 1377: [15].

\section{Results and Discussion}

The results from the preliminary tests (grain size analysis, natural moisture contents, specific gravity, and Atterberg's limits test) as well as the engineering test (compaction test, California Bearing Ratio test and triaxial test) are presented and discussed below.

\subsection{Preliminary Test}

The summary of the preliminary test results for soil samples A, B, C are shown in Table 1 . The natural moisture content of the selected soil samples A, B and C are 7.06\%, 7.87\% and $7.68 \%$ respectively. The result showed that sample $\mathrm{B}$ has the highest natural moisture content and sample A the lowest. Lambe and Whiteman [16] stated that the moisture content of a soil 
depends largely on void ratio, thus the results could be attributed largely to the void and the specific gravity. Sample A probably has a largest void ratio compared to the others. These also show that the soil samples still contain some appreciable amount of moisture, which is largely affected by the climatic condition. The specific gravity of samples A, B and C are 2.684, 2.500 and 2.273 respectively. These values ranges within what Das [3] stated, that for most clay minerals, there specific gravity fall within a general range (1.6-3.2), a Halloysite (1.60-2.55) and Biotite (2.8-3.2) which indicated that the soils are Halloysites. AASHTO soil classification system was used in the classification of the soil samples, the particle size analysis showed values of $67.4 \%, 51.2 \%$ and $61.2 \%$ passing the No. 200 sieves for Samples A, B and C respectively. Fajobi [17], classified soil into seven major groups A-1 to A-7, soil classified under groups A-1, A-2, A-3 are granular materials while soil classified under groups A-4, A-5, A-6 and A-7 is mostly silt and clay-type materials. Soil samples A, B and C classified as A-5 to A-7 according to the AASHTO table for classification [18] and the subgrade rating is rated as fair to poor and therefore will require stabilization as established by Sobhan and Das, [19].

Table 1: Summary of preliminary test for soil samples

\begin{tabular}{|c|c|c|c|c|c|c|}
\hline Sample & $\begin{array}{c}\text { Natural } \\
\text { Moisture } \\
\text { Content } \\
(\%)\end{array}$ & $\begin{array}{c}\text { Specific } \\
\text { Gravity }\end{array}$ & $\begin{array}{c}\text { Percent } \\
\text { retained (\%) }\end{array}$ & $\begin{array}{c}\text { Liquid } \\
\text { Limit (LL) } \\
(\%)\end{array}$ & $\begin{array}{c}\text { Plastic } \\
\text { Limit } \\
(\mathrm{PL})(\%)\end{array}$ & $\begin{array}{c}\text { Plastic } \\
\text { Index (PI) } \\
(\%)\end{array}$ \\
\hline $\mathrm{A}$ & 7.06 & 2.684 & 67.40 & 73.88 & 27.27 & 46.61 \\
\hline $\mathrm{B}$ & 7.87 & 2.500 & 51.20 & 65.95 & 33.72 & 32.23 \\
\hline C & 7.68 & 2.273 & 61.20 & 60.40 & 30.83 & 29.57 \\
\hline
\end{tabular}

\subsection{Cement stabilization}

The liquid limits, plastic and plasticity index of $73.88 \%, 27.27 \%$ and $46.61 \%$ for sample A, $65.95 \%, 33.72 \%$ and $32.23 \%$ for sample B, $60.40 \%, 30.83 \%$ and $29.57 \%$ for sample C respectively without any additives. Gidigasu [20], stated that liquid limit less than 35\% indicates low plasticity, between $35 \%$ and $50 \%$ indicates intermediate or medium plasticity, between $50 \%$ and $70 \%$ high plasticity and between $70 \%$ and $90 \%$ very high plasticity. On this note, the three samples have high plasticity. There was overall improvement in the plasticity of the samples as the variation in results of the Atterberg's limits tests for the soil samples on addition of the optimum cement dosage of $11 \%$ based on the Unified Soil Classification System showed significant reduction in both liquid limits and plasticity index and increase in plastic limits for all the soil samples as shown in Figures 2 to 4 for samples A, B and C respectively, further improvement observed in both samples as there were further reduction in both the plastic limit and plasticity index on addition of $11 \%$ cement and 6\% pulverized snail shell (PSS). 


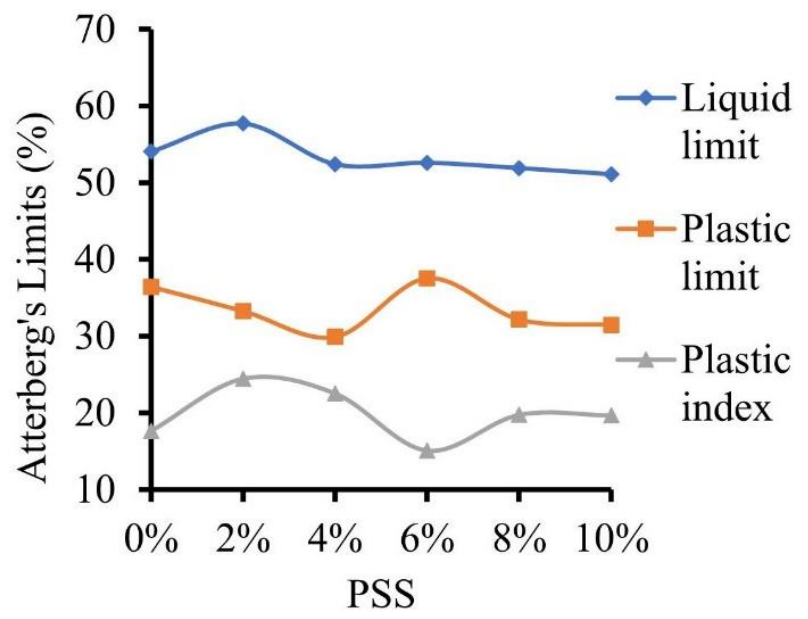

Figure 2: Variation of Atterberg limits with varying PSS at fixed 11\% cement dosage for Sample A

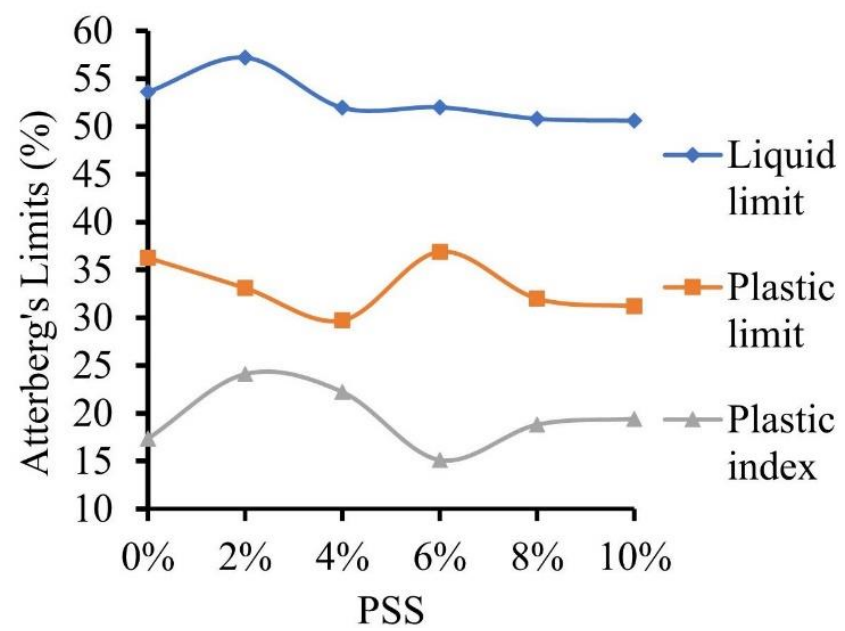

Figure 3: Variation of Atterberg limits with varying PSS at fixed $11 \%$ cement dosage for Sample B 


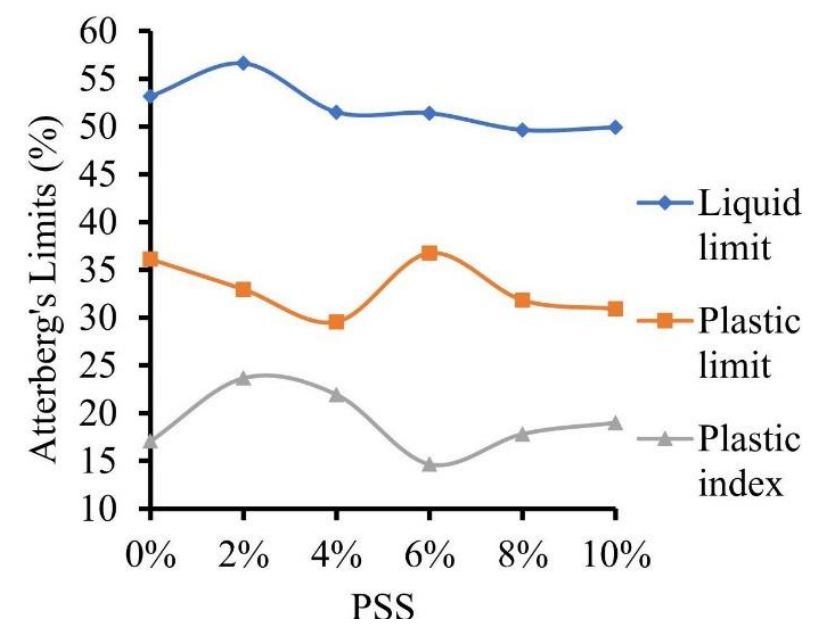

Figure 4: Variation of Atterberg limits with varying PSS at fixed 11\% cement dosage for Sample C

The reduction in plasticity index exhibited by all the three samples shows the effect of addition of $11 \%$ cement and $6 \%$ PSS for all the soil samples. Das [21] explained that cement can be used to stabilize sandy and clayey soils. As in the case of lime, cement helps decrease the liquid limit and increase the plasticity index and workability of clayey soils. Which is effective for clayey soils when the liquid limit is less than 45 to 50 and the index is less than about 25 .

\subsection{Engineering Strength Tests}

The compaction test was carried out to determine the optimum moisture content (OMC) and the maximum dry density (MDD) of the three soil sample at the natural state, stabilization with optimum cement dosages and addition of the pulverized snail shell (PSS).

The natural soil sample has an OMC of $24.07 \%, 24.5 \%, 25.67 \%$ and an MDD of $1493.34 \mathrm{~kg} / \mathrm{m}^{3}$, $1476.77 \mathrm{~kg} / \mathrm{m}^{3}, 1460.77 \mathrm{~kg} / \mathrm{m}^{3}$ for sample A, B and C respectively. Stabilization with $11 \%$ cement reduced the OMC to $22.33 \%$ and increased the MDD to $1632 \mathrm{~kg} / \mathrm{m}^{3}$ for sample A, reduced the $\mathrm{OMC}$ to $22.5 \%$ and increased the MDD to $1668 \mathrm{~kg} / \mathrm{m}^{3}$; for sample $\mathrm{B}$, reduced the $\mathrm{OMC}$ to $21.27 \%$ and increased the MDD to $1651 \mathrm{~kg} / \mathrm{m}^{3}$ for sample $\mathrm{C}$. The increase in the MDD can be attributed to the replacement of the soil by the cement particles which have lower specific gravity compared to that of the soil. It may also be attributed to coating of the soil by the powdery cement which result to large particles with larger voids and hence less density [22]. Lambe and Whiteman [16] stated that, for good soil, the lower the OMC, the better its workability and an increase in dry density is an indicator of soil improvement. The decrease in OMC with addition of cement can be attributed to increasing demand for water by various cations and the clay mineral particles to undergo hydration reaction. The addition of PSS at $(2 \%, 4 \%, 6 \%, 8 \%$, and $10 \%)$ and $11 \%$ cement to the soil samples caused a decrease in the MDD and an increase in OMC of all the soil samples. The increase in the OMC confirmed the pozzolanic behavior of PSS with an increasing demand for water to react and form aggregate molecules in the soil. Table 2 showed the result of MDD and OMC of the variation in mix percentage of PSS at optimum cement dosage. 
Table 2: Summary of Compaction test on cement stabilized samples and varying pulverized snail shell (PSS)

\begin{tabular}{|c|c|c|c|}
\hline Samples & $\begin{array}{l}\text { Percentage } \\
\text { Stabilization } \\
\text { (\% PSS })\end{array}$ & $\begin{array}{l}\text { Optimum Moisture } \\
\text { Content }(\%)\end{array}$ & $\begin{array}{ll}\text { Maximum } & \text { Dry } \\
\text { Density }\left(\mathrm{kg} \cdot \mathrm{m}^{-3}\right) & \end{array}$ \\
\hline \multirow{6}{*}{ A } & 0 & 22.33 & $1632 \pm 435.81$ \\
\hline & 2 & 25.04 & $1621 \pm 411.43$ \\
\hline & 4 & 26.70 & $1627 \pm 409.86$ \\
\hline & 6 & 25.04 & $1650 \pm 399.45$ \\
\hline & 8 & 25.75 & $1611 \pm 409.82$ \\
\hline & 10 & 30.52 & $1541 \pm 422.63$ \\
\hline \multirow{6}{*}{ B } & 0 & 22.50 & $1668 \pm 202.58$ \\
\hline & 2 & 25.01 & $1655 \pm 186.97$ \\
\hline & 4 & 25.68 & $1612 \pm 309.34$ \\
\hline & 6 & 25.03 & $1634 \pm 278.65$ \\
\hline & 8 & 24.52 & $1638 \pm 266.69$ \\
\hline & 10 & 31.49 & $1525 \pm 213.24$ \\
\hline \multirow{6}{*}{$\mathrm{C}$} & 0 & 21.27 & $1651 \pm 135.45$ \\
\hline & 2 & 26.99 & $1642 \pm 198.23$ \\
\hline & 4 & 25.66 & $1595 \pm 200.61$ \\
\hline & 6 & 26.01 & $1611 \pm 166.03$ \\
\hline & 8 & 23.51 & $1621 \pm 133.05$ \\
\hline & 10 & 32.50 & $1510 \pm 176.52$ \\
\hline
\end{tabular}

The unsoaked CBR values for the natural and cement-stabilized soil samples is shown in Figure 5. The CBR test were conducted at OMC of the soil, soil-cement or soil cement-PSS as determined from the compaction test. The CBR tests were performed immediately after compaction. The unsoaked CBR values for the natural soil were found to be $3 \%$ for samples A and $\mathrm{C}$ and $2 \%$ for sample B. Stabilization with $11 \%$ cement increased the CBR value of sample A to $12 \%$, sample B to $13 \%$ and $11 \%$ for sample C. Results of the unsoaked CBR fluctuated when addition of PSS at $(2 \%, 4 \%, 6 \%, 8 \%, 10 \%)$ and $11 \%$ optimum cement were introduced to the three soil samples with $4 \%$ PSS and $11 \%$ cement shows the highest value CBR value for all the samples. 


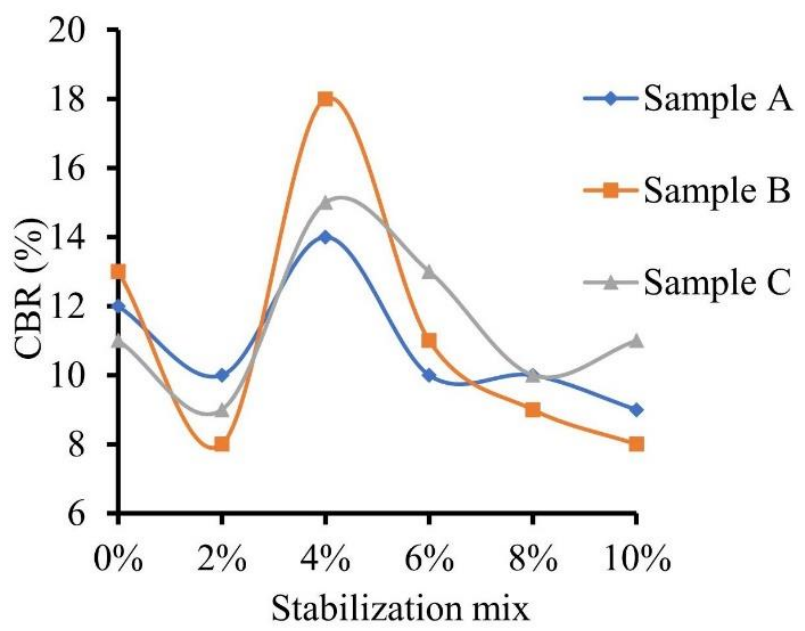

Figure 5: Variation of California bearing ratio with increasing PSS at $11 \%$ cement dosage

Figure 6 shows the variation of the shear strength with increasing PSS content. The shear strength values of samples are $56.48 \mathrm{kPa}, 51.45 \mathrm{kPa}$ and $48.05 \mathrm{kPa}$, at natural state and $85.81 \mathrm{kPa}$, $75.17 \mathrm{kPa}$ and $72.31 \mathrm{kPa}$ when stabilized at optimum cement of $11 \%$ for samples A, B, and C respectively. The addition of $2 \% \mathrm{SSP}$ decreased the shear strength to $59.98 \mathrm{kPa}$ sample A, $66.72 \mathrm{kPa}$ sample B and increased to $80.89 \mathrm{kPa}$ for sample C. For sample A, the addition of $4 \%$ PSS, increased the shear strength but later decreased on addition of $6 \%, 8 \%, 10 \%$ PSS. For sample B, the addition of PSS at $4 \%$ and $6 \%$ PSS increased the shear strength but decreased on addition of $8 \%, 10 \%$ PSS. For sample $\mathrm{C}$, the addition of PSS at $4 \%, 6 \%$ and $8 \%$ increased the shear strength values but and later decreased on addition of $10 \%$.

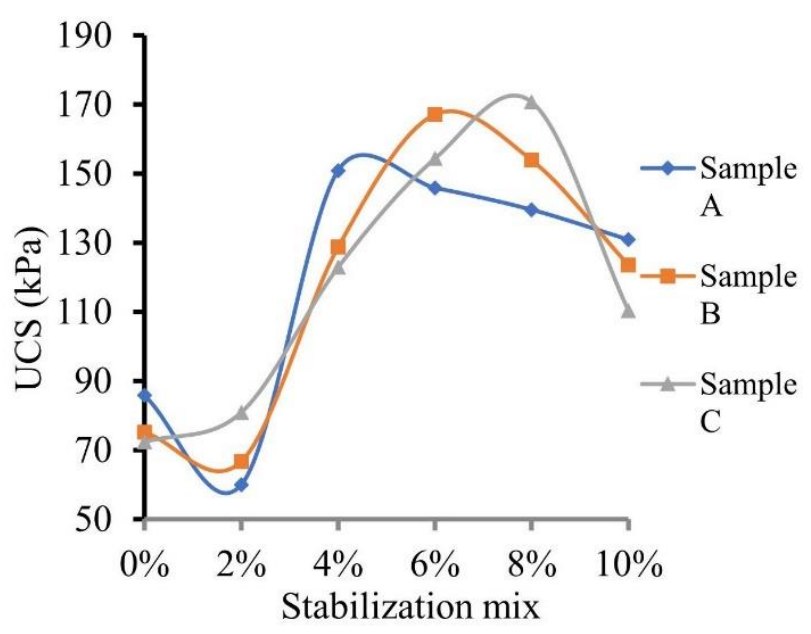

Figure 6: Variation of unconfined compressive strength with increasing PSS at $11 \%$ cement dosage 


\section{Conclusion}

The cement stabilized with pulverized snail shell to subsoil showed significant improvement in the properties of the soil generally. The addition of $11 \%$ optimum cement reduced the liquid limit of soil samples A, B and C and a further reduction were noticed when PSS at $4 \%, 6 \%, 8 \%$ and $10 \%$ were added for all samples. Stabilization with $11 \%$ cement reduced the optimum moisture content and increased the maximum dry density of soil samples, for most soils, the lower the OMC, the better its workability and an increase in dry density is an indicator of soil improvement.

The unsoaked CBR values for the cement stabilized soil samples increased with the addition of optimum percentage of $11 \%$. The CBR values for the cement-stabilized soil samples A and B further increased with addition $4 \%$ PSS, for sample C, the increase was at both $4 \%$ and $6 \%$ PSS. There was substantial increase in shear strengths for the cement stabilized soil samples and addition of PSS on the cement stabilized soil samples at all percentages, the highest shear strengths being observed at $4 \%, 6 \%$ and $8 \%$ PSS for all soil samples. The optimum stabilization value ranges between $4 \%$ to $8 \%$ pulverized snail shells for cement stabilized samples. In summary, this study has shown through literature review and experimental work that pulverized snail shell is a good complement for cement stabilization in lateritic soils.

\section{References}

[1] Murthy, V.N.S., (2002). Geotechnical Engineering. Marcel Dekker, Inc, New York.

[2] Cuneyt, T., (2000). Synthesis of Biomimetic Ca-Hydroxyapatite Powders at $37^{\circ} \mathrm{C}$ in Synthetic Body Fluids. Biomaterials 21:1429-1438.

[3] Das, B. M., (2000). Fundamentals of Geotechnical Engineering. Thompson Learning California.

[4] Ingles, O. G., and Metcalf, J. B., (2002). Soil Stabilization Principles and Practice. Butterworth's Publishers Boston.

[5] Pyne, A. L., (1995). Comparative Biochemistry and Physiology Volume 29 (Issue 2), May 2001, Pages 611-620.

[6] Lopez, E. D., and Castano, P. K., (2001). Foundation Design and Construction, 7th ed. Pearson Educational Limited. Harlow, England.

[7] Ghafoori, R., and Cai, W., (1997). Introduction to Geotechnical Engineering, PrenticeHall, Inc Englewood Cliffs, New Jersey.

[8] Muntohar, G. D., and Gendut, K. A., (2000). Soil Mechanics in Engineering Practice 3rd $E d$., John Wiley \& Sons, Inc.

[9] Muntohar, G. D., (1999). Soil Mechanics in Engineering Practice 3rd Ed., John Wiley \& Sons, Inc.

[10] Zaid, S. T., and Ghorpade, V. G. (2014a). Experimental Investigation of Snail Shell Ash as Partial Replacement of Ordinary Portland Cement in Concrete. International Journal of Engineering Research and Technology (IJERT) Vol. 3 (Issue 10). 
[11] Microsoft® Student, (2009). DVD, Snail, Redmond, WA: Microsoft Corporation.

[12] Kovacs, W.D., and Holtz, R.D., (1981). Introduction to Geotechnical Engineering. 2nd ed. Prentice-Hall, Pearson Educational Limited.

[13] British Standards (BS) 1924. (1990a). Methods of Test for Stabilized Soils. British Standards Institutions. London, U. K.

[14] ASTM C618-93 Specification (1992). Fly Ash and Raw or Calcined Natural Pozzolan for Use as mineral Admixture in Portland Cement Concrete. Washington, D.C.

[15] British Standards (BS) 1377-1 (2016). Methods of test for soils for civil engineering purposes. General requirements and sample preparation.

[16] Lambe, T. W., and Whiteman, R. V., (1979). Soil Mechanics, John Wiley and Sons Inc, USA.

[17] Fajobi, A.B., (2008). Unpublished Lecture Notes on Geotechnical Engineering I, Department of Civil Engineering, Faculty of Technology, Obafemi Awolowo University, Ile-Ife.

[18] AASHTO, (1986). Soil Classification System (from AASHTO M 145 or ASTM D3282)

[19] Sobhan, K., and Das, B. M. (2007) Durability of Soil-Cements against Fatigue Fracture. Journal Materials in Civil Eng., 19(1): 26-32.

[20] Gidigasu, M.D., (1973). Degree of Weathering in the Identification of Laterite Materials for Engineering Purposes, Journal of Engineering Geology, Vol. 8, No. 3: 213-266.

[21] Das, B. M., (2008). Advanced Soil Mechanics, 3rd Edition, CRC Press, New York, Emmanuel, Visual Inspection of Concrete, http://www.montrealhomeinspectorpro.ca/en/home-inspection-articles/view/560/VisualInspection-of-Concrete

[22] Guyer, J. P., Guyer, P. E., and Guyer, R. A., (2011). An Introduction to Soil Stabilization for Pavements. Continuing Education and Development, Inc, New York. 